\title{
From Gentleman to Player
}

Whatever future is decreed for the Family Planning Association by the negotiations now in progress with the Department of Health and Social Security, it is no mean triumph that the government has finally acknowledged an active responsibility in this area. Concern about the growth of Britain's population, which may in part have prompted this change of heart, is an entirely separate and on the whole less pressing issue than that of providing all who need it with genuine access to modern methods of contraception. At present that access is denied, as the abortion rates alone will testify. But this is not to detract from the major expansion that the Family Planning Association has undergone in the last five years. It has doubled the number of clinics and raised to more than half a million the number of people who seek advice from them each year. The expansion has, of course, been helped by the 1967 Family Planning Act which empowered, but did not compel, local authorities to provide contraceptive services to all who required them, regardless of marital status. But the Association has had an uphill task to take advantage of this long overdue legislative support-according to a recent survey, only a quarter of the local authorities are now providing the full services recommended by the act.

The recent expansion has hastened the transition of the Family Planning Association from voluntary to professional status. The days of the great pioneers and of wrestling with the prejudices of the medical profession are ending, though not yet over. But now that the battle for public support has been largely won, the Family Planning Association is divided as to what its next goal should be. It is natural that differences of opinion should arise between those who see the major task of the Association as being to dispense contraceptive advice to the maximum number of people and others, particularly the medical staff, who wish to give consultation on sexual problems to a smaller number of people.

These differences may have been responsible for the recent resignation of Dr Hilary Hill, the deputy director (medical), which seems to have hastened the Association's plans for reviewing the medical side of its activities. A commission under Lord Platt has now recommended that the Association appoint a chief medical officer who would be backed by a smaller and more active panel of advisers than the present medical council. These proposals, which have been accepted by the national executive committee of the Association, reflect the growing technicalities of contraceptive practice and the need for the Association to provide authoritative medical opinions on advances in reproductive technology as well as on occasions when government committees or newspapers provoke unnecessary despondency about the pill.

The side-effects of the pill that are now reaching statistical significance have produced several kinds of headache for family planning administrators. There is not just the flight from the pill that alarmist pronouncements engender. The proliferation of medical tests which doctors like to give before prescribing the pill may reassure some women but inhibits others, particularly those who are liable to be intimidated by the elinical procedures. Unfortunately it seems that the latter category includes the type of women who stand most in need of family planning advice. This is one of the questions that is to be studied by the major survey of family planning services that is to be mounted shortly by the Department of Health and Social Security. The future status of the Family Planning Association may well be affected by the negotiations now under way, but even if in the name of integration the Association disappears into the arms of the health service, there could be no more significant tribute to the way in which it has tackled responsibilities which governments have shirked for so long.

\section{Yeurs Ago}

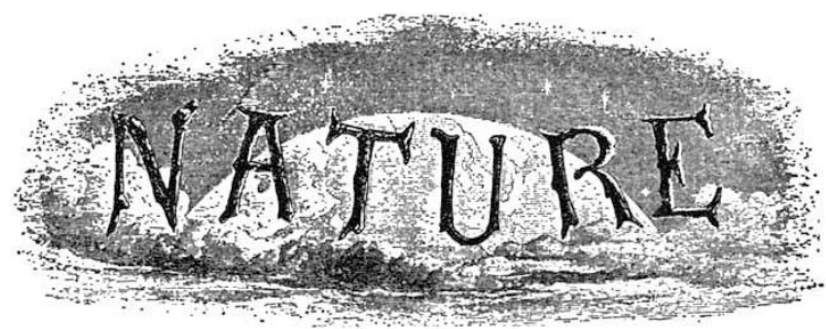

The Royal Society

I CANNOT but think that the list of candidates recommended by the Council for election into the Royal Society published in your last number will be read by the outside world with considerable surprise. I look in vain in it for the names of two men, at least, of world-wide reputation, and well known as no mere dilcttanti in their respective sciences, who were among the candidates, while the names of others are found there, which are on everybody's lips with the thought, What have they done to merit the scientific distinction which is looked on by every lover of science as almost an opening of the gates of paradise? Is it possible for us outsiders to learn anything of the considerations which govern the election? NO'T AN F.R.S.

Tre British Medical Fournal states that the chair of Physiology, in the University of Prague, vacant by the death of the celebrated Purkinje, has been filled by the appointment of Dr. Hering, of Vienna. It was offered to Professor Helmholtz, who, however, preferred to remain at Ileidelberg.

A RECENT number (94) of the German series known as "A Collection of Popular Scientific Treatises, edited by R. Virchow and Fr. von Holtzendorff," is a lecture on the Glacial Period (Die Eiszeit der Erde), by Alexander Braun. It gives a clear and concise history of the observations and arguments by which geologists have been led to the conclusion that a lengthened period of extreme cold overspread the greater part of Europe before the commencement of the historical epoch.

From Nature, 2, 48 and 51, May 19, $18 \% 0$. 